\title{
Frailty as a risk predictor in cardiac surgery: Beyond the eyeball test
} \author{
Rakesh C. Arora, MD, $\mathrm{PhD}^{\mathrm{e}, \mathrm{f}}$
}

Bobby Yanagawa, MD, PhD, ${ }^{\mathrm{a}}$ Michelle M. Graham, MD, ${ }^{\mathrm{b}}$ Jonathan Afilalo, MD, ${ }^{\mathrm{c}}$ Ansar Hassan, $\mathrm{MD},{ }^{\mathrm{d}}$ and

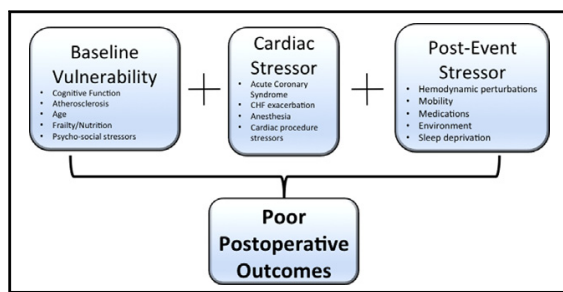

Three-strikes model of frailty, adapted with permission from Arora and colleagues.

Central Message
A frailty outcome modifier in cardiac surgery is
described. The identification of preoperative
frailty improves risk prediction and provides
targets for optimization for enhanced recovery
after cardiac surgery.

See Editorial Commentary page 177.

Supplemental material is available online.

Over the past 50 years, there have been dramatic improvements in cardiac surgical processes and outcomes that allow for procedures to be performed safely on older and sicker patients. In the current era of cardiac surgery, those aged 75 years and older represent a growing subset of patients, and the level of frailty ranges between $25 \%$ and $50 \%$ of these patients depending on the type of assessment tool used. $^{1,2}$

Successful surgical correction of cardiac disease has the potential to restore biologic function and provide substantial benefit even for older adult patients. ${ }^{3,4}$ However, conventional cardiac surgery is associated with substantial iatrogenic stress, which can affect outcomes. Frail patients are vulnerable in that they are more susceptible to the complexity of surgical process, are at greater risk for complications after surgery, and are less likely to recover function postoperatively (Figure 1).

\section{WHAT IS FRAILTY AND IS IT A RISK PREDICTOR IN CARDIAC SURGERY?}

Frailty is a syndrome characterized by vulnerability to stressors due to loss of physiologic reserve. The phenotype of frailty encompasses the patient factors of exhaustion, malnutrition, wasting, weakness, slowness, and inactivity. ${ }^{6}$ Often seen in the older adult, frailty is an important but still underused determinant of treatment outcome in cardiac surgery. The literature has largely focused on the biological or physical aspects of frailty as a risk factor; however, more recently there is greater appreciation for the psychologic and social aspects of frailty, which may also result in negative postoperative outcomes. ${ }^{7,8}$

Chronologic age is inextricably linked to frailty but should not be the sole determinant in determining operative vulnerability or assignment of treatment futility. Younger patients can also be frail. In fact, the Canadian Health Measures Study determined that the prevalence of frailty was $2 \%$ to $5 \%$ in those aged 18 to 34 years, $4 \%$ to $6 \%$ in those aged 35 to 49 years, $7 \%$ to $12 \%$ in those aged 50 to 64 years, and $8 \%$ to $20 \%$ in those aged $65+$ years. ${ }^{9}$ We tend to associate frailty with low body mass index because obese patients tend to have greater metabolic reserve and can cope better with catabolic stimuli seen in chronically advanced heart failure and acutely in cardiac surgery: This is referred to as the "obesity paradox." ${ }^{10}$ However, obese patients can also be frail, a phenomenon referred to as "sarcopenic obesity." Sarcopenia is an age-associated decline in skeletal muscle that when coupled with obesity can beget frailty, disability, and adverse cardiovascular outcomes linked to metabolic syndrome. ${ }^{11}$ The major issue is the low muscle mass, associated with low metabolic reserve and poor coping with catabolic stimuli, and not the excess fat mass.

There are now ample data to support the notion that frailty is a risk predictor for poor outcomes after cardiac 
surgery. A recent systematic review demonstrated the association between frailty and adverse outcomes, which was particularly true for older patients undergoing transcatheter aortic valve replacement (TAVR). ${ }^{12}$ Frailty was also associated with a 3-fold increase in mortality among older adult patients in a multicenter prospective database. ${ }^{13}$ Not surprisingly, frailty is also independently associated with prolonged length of stay, need for critical care resources, discharge to specialized facilities, and readmission to hospital, suggesting an even higher surgery-related healthcare cost burden.

\section{HOW DO WE MEASURE FRAILTY?}

Traditionally, surgical teams have evaluated frailty by the end-of-bed "eyeball test." "Eyeballing," although of some value, is subjective and tends to be inconsistent with poor inter-rater reliabilty. ${ }^{14}$ By way of analogy, one cannot judge the state of a car by simply examining the outward appearance alone. One needs to open the hood and take a look at the engine for a proper evaluation. To facilitate a more granular examination of the preoperative older adult, there are more than 20 different validated objective assessment tools for frailty, but at present there is no widely accepted, standardized measure for cardiac surgical patients (Table E1). ${ }^{15}$ This reflects the multifaceted nature of frailty in later life, as well as the unique perspective taken by individual researchers and clinicians. ${ }^{15}$ That being said, it would appear that using any frailty assessment (other than the eyeball test) is likely better at predicting mortality, major adverse cardiac events, ${ }^{12}$ and other adverse outcomes (ie, delirium ${ }^{1}$ and long-term term health-related quality of life outcomes ${ }^{2}$ ). In the following section, a general description of the broad categories of frailty assessments are provided, as well as practical suggestions of what tools are "feasible" to consider within the limitations of the current literature for the patient undergoing cardiac surgery.

There are 2 broad types of frailty assessment tools: phenotypic and index-based tools. A phenotype describes a set of observable characteristics. For example, the Fried frailty phenotype defines 5 key domains: slow gait speed, weak handgrip strength, unintentional weight loss, and questionnaire-based assessments of low physical activity and exhaustion. ${ }^{6}$ Fried and colleagues ${ }^{6}$ conceptualize frailty as a distinct biologic syndrome and as such does not include medical comorbid conditions. Those with impairment in 3 or more of the 5 domains are considered frail. The Rockwood frailty index (FI) approach, on the other hand, conceptualizes frailty in terms of the numeric count of deficits, which can be loosely defined as age-related conditions, signs, symptoms, or disabilities that are associated with poor prognosis. ${ }^{16}$ In brief, the FI approach seeks to mathematically determine the ratio of deficits present in an individual person to the total number deficits that are being considered. Converse to a dichotomized approach (ie, frailty is present or not), an FI can be treated as a continuous variable allowing the gradation frailty severity (note FI of 0.21 is consistent with mild frailty). Although 92 candidate deficits were originally identified to assess the FI, it was subsequently determined that as few as 30 provide sufficient resolution for effective measurement. There are also single performance measures such as the chair rise test, timed up and go test, and others, which can be rapidly performed in a clinical setting.

The optimal frailty assessment for cardiac surgical patients should have high predictive ability, should be quick and easy to perform (or calculate), and, if a performance measure, should be practical for most patients awaiting surgery. Several assessments have been shown to be predictive for clinical outcomes in patients undergoing cardiac surgery. ${ }^{17,18}$ Afilalo and colleagues ${ }^{19}$ found that slow preoperative gait speed had a 2- to 3-fold increased risk predictive ability beyond the Society of Thoracic Surgery-Predicted Risk of Mortality or Major Morbidity and European System for Cardiac Operative Risk Evaluation (euroSCORE). Recently, Afilalo and colleagues ${ }^{20}$ performed a prospective, multicenter study of head-to-head comparison of frailty assessments in elderly patients undergoing TAVR versus surgical aortic valve replacement to determine which frailty assessment optimally predicted all-cause mortality and disability. The 4-item Essential Frailty Toolset, encompassing lower-extremity weakness, cognitive impairment, anemia, and hypoalbuminemia, best predicted mortality, disability at 1 year, and death at 30 days (Figure 2).

The Clinical Frailty Scale (CFS) is another practical instrument that could be used at the bedside to initiate the process of frailty screening by the perioperative team that has no prior process for frailty assessments at their center. The CFS, a tool born from a mathematical accumulation of deficit model of frailty, can function as a standardized eyeball test for determining frailty status on the basis of a categorized, subjective clinical judgment of the evaluator and may be a reasonable first choice in making frailty assessments. ${ }^{16}$ Frailty status as defined by a CFS score greater than 4 could serve as an indication to a clinician to initiate frailty-targeted management (Table 1).

\section{CAN FRAILTY ASSESSMENT HELP TO DETERMINE WHETHER THERE IS A NET CLINICAL BENEFIT OF SURGERY?}

Incorporating health priorities near the end of life has long been a part of decision-making for patients who undergo certain cardiac procedures. Innovations in percutaneous coronary intervention, TAVR, and transcatheter mitral interventions have intensified interest in frailty more broadly. For instance, frailty has become a key selection criterion for use of TAVR versus surgical aortic valve replacement. Gradients of frailty also became relevant to select those who would most benefit. The incorporation of 


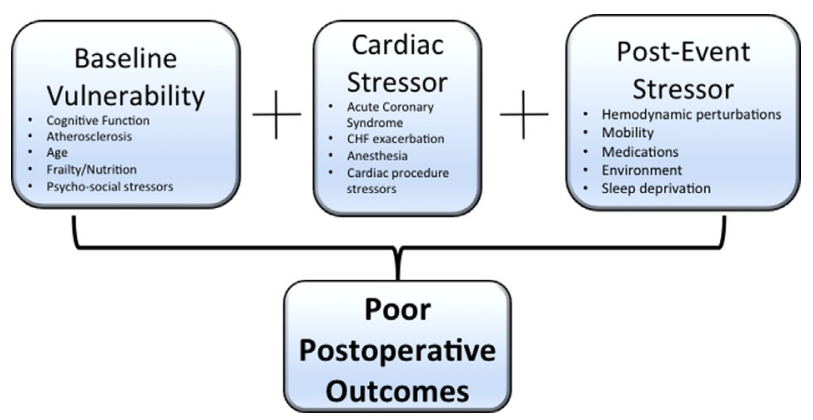

FIGURE 1. Three-strikes model of frailty. $\mathrm{CHF}$, Congestive heart failure. (Adapted with permission from Arora and colleagues. ${ }^{5}$ )

frailty should be part of the patient evaluation process to better conceptualize discussion of desired outcomes facilitating shared decision-making and palliative care discussion within a value-based health care paradigm.

\section{HOW CAN RISK SCORES INCORPORATE FRAILTY MEASURES?}

It is clear that we need improved decision tools for surgical treatment of the frail. The 2 major scoring systems that are commonly used to predict the risk of negative outcomes after cardiac surgery are the Society of Thoracic SurgeryPredicted Risk of Mortality or Major Morbidity and the euroSCORE II. The euroSCORE II typically overestimates perioperative risk, whereas the Society of Thoracic Surgeons score underestimates perioperative risk in frail

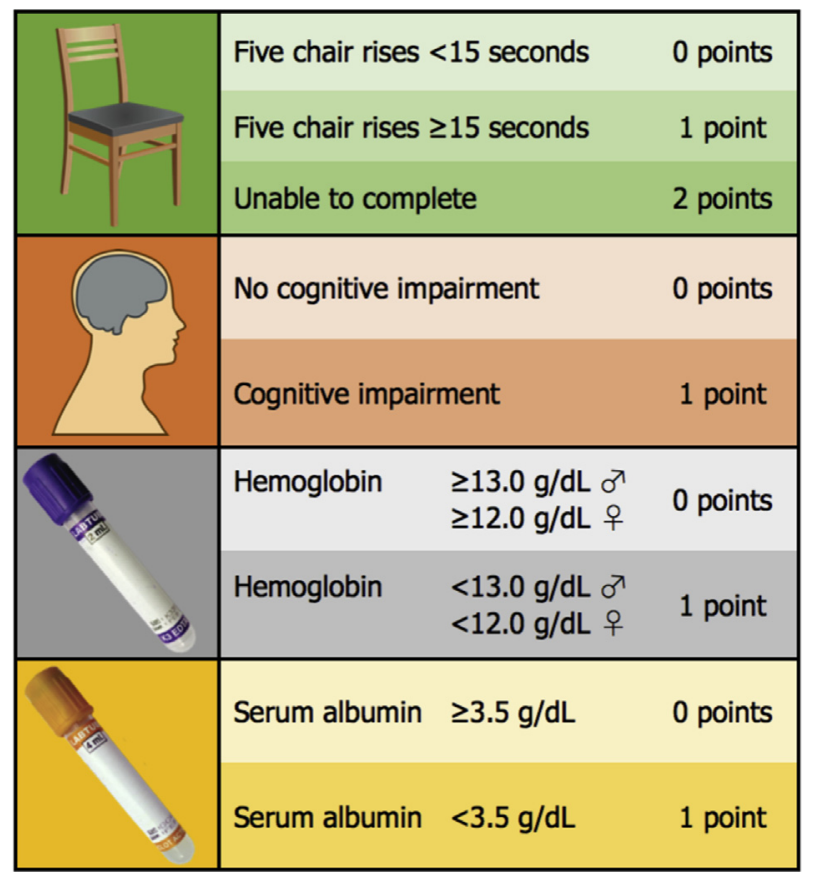

FIGURE 2. Essential frailty toolset in older adults undergoing aortic valve replacement. Adapted with permission from Afilalo and colleagues. ${ }^{20}$
TABLE 1. Canadian study of health and aging clinical frailty scale

\begin{tabular}{|c|c|}
\hline Score & Description \\
\hline 1 & $\begin{array}{l}\text { VERY FIT-robust, active, energetic, well motivated, and fit; } \\
\text { these people commonly exercise regularly and are in the } \\
\text { most fit group for their age }\end{array}$ \\
\hline 2 & $\begin{array}{l}\text { WELL-without active disease, but less fit than people in } \\
\text { category } 1\end{array}$ \\
\hline 3 & $\begin{array}{l}\text { WELL, WITH TREATED COMORBID DISEASE-disease } \\
\text { symptoms are well controlled compared with category } 4\end{array}$ \\
\hline 4 & $\begin{array}{l}\text { APPARENTLY VULNERABLE-although not frankly } \\
\text { dependent, these people commonly complain of being } \\
\text { "slowed up" or have disease symptoms }\end{array}$ \\
\hline 5 & $\begin{array}{l}\text { MILDLY FRAIL-with limited dependence on others for } \\
\text { instrumental activities of daily living }\end{array}$ \\
\hline 6 & $\begin{array}{l}\text { MODERATELY FRAIL-help is needed with both } \\
\text { instrumental and noninstrumental activities of daily living }\end{array}$ \\
\hline 7 & $\begin{array}{l}\text { SEVERELY FRAIL-completely dependent on others for the } \\
\text { activities of daily living, or terminally ill }\end{array}$ \\
\hline
\end{tabular}

patients. ${ }^{21,22}$ The exhaustive list of variables entered into the models does not include frailty. Although these tools have incorporated age, both models, in their current iteration, focus on "traditional" physiology variables and thus provide information limited to the patient's physiologic vulnerability. It is becoming increasingly evident that a more comprehensive assessment that involves the psychologic and social frailty assessments because part of their algorithm is necessary for the contemporary cardiac surgery patient.

To this point, the Society of Thoracic Surgeons has included 5-m gait speed as a marker of frailty in their most recent iteration of the adult cardiac surgery database (Version 2.73). The involvement of one, easily measured parameter of frailty is a step in the right direction but is not deliverance and alone does not capture the true impact of frailty on individual patient scores. Greater incorporation of frailty assessment into clinical databases and clinical risk scores for cardiac surgery patients will provide surgeons and their patients with important information about risk and assist with shared decision-making as well as arming health economists with information to plan healthcare costs. With the aging cardiac surgery demographic, it is necessary for registries to include measures of frailty to permit longitudinal analysis of outcomes after intervention decisions in the frail older adult. It is equally necessary for clinical trials to collect measures of frailty to catalyze comparative effectiveness research testing the differential risks and benefits of interventions in frail versus nonfrail patients. The goal is to ensure that patients not only survive after cardiac surgery but also thrive, with the maintenance of acceptable healthrelated quality of life and functional independence. ${ }^{23}$ Indeed, a question that the cardiac surgery community must start to consider is whether poor outcomes in the frail 
older adult should serve as a quality metric of a cardiac surgical program.

\section{CAN WE "DEFRAIL" THE OLDER ADULT CARDIAC SURGERY PATIENT?}

Beyond frailty assessments, identification of at-risk frail individuals, and the evaluation of risk versus benefit in these patients, consideration must be given to how frail patients may be better prepared for their procedure. For elective patients, identification of frailty may trigger the initiation of preoperative rehabilitation or "prehab." Building on work by Arthur and colleagues, ${ }^{24}$ a small pilot randomized controlled trial of prehab $(\mathrm{n}=7)$ versus standard care $(\mathrm{n}=8)$, including exercise and education classes for $60 \mathrm{mi}-$ nutes/day, twice weekly for at least 4 weeks versus standard care $(\mathrm{n}=8)$, was carried out for patients undergoing coronary artery bypass grafting and valvular surgery. ${ }^{25}$ Although there were no differences in hard clinical outcomes, patients in the prehab group experienced improvement in walk distance and gait speed compared with baseline and higher enrollment in cardiac rehabilitation when compared with the standard care group.

Pre-operative Rehabilitation for Reduction of Hospitalization After Coronary Bypass and Valvular Surgery (PRE$\mathrm{HAB}$ ) is a multicenter, randomized, open end point, controlled trial using assessor blinding and intent-to-treat analysis that is currently under way to better examine the effect of prehab in the setting of frailty (ClinicalTrials.gov NCT02219815). Frail, older adult cardiac surgical patients are being recruited and randomized to receive standard of care or an 8-week exercise and education intervention at a certified medical fitness facility ( 2 times per week; aerobic exercise at $40 \%-60 \%$ of heart rate reserve). The primary outcome of the trial is proportion of patients requiring a hospital length of stay greater than 7 days.

\section{INTERDISCIPLINARY TEAM}

The concept of Interdisciplinary Team-based care has generated great interest and support from major practice guidelines in cardiology and cancer care, among other fields. For elective patients, a geriatrics consult could help to identify vulnerable patients, correct reversible frailtyrelated preoperative patient characteristics, and help the team provide better care for such patients in the postoperative period. Other key members of the interdisciplinary team may include physiotherapists, nutritionists, and social workers.

\section{AN ECONOMIC ARGUMENT}

Health care systems will have to plan for the large increase in aging among the world's population. By the year 2050 , it is estimated that the population of those aged 65 years will grow to 2 billion. Care of the frail and older adult consume a disproportionate and increasing proportion of our healthcare dollars. A recent report highlighted an approximately $30 \%$ increase in hospitalization cost associated with cardiac surgery in frail patients. ${ }^{26}$ The fact that cardiac surgery in frail patients is more costly in and of itself is not surprising, given that the older adult is more prone to longer intensive care unit stays, greater rates of complications, greater blood product use, higher likelihood of transfer to rehabilitation and other nonhome facilities, and hospital readmission and homecare services, all of which drive excess costs.

An often-pondered economic question is whether undertaking cardiac surgery procedures in frail patients is an appropriate use of our limited healthcare dollars. To answer this question, we need to better understand the direct and indirect costs associated with nonoperative (medical and interventional) management of such frail patients, including costs of increased follow-up care, recurrent hospitalizations, and so forth, that may result from the inadequate resolution of the primary problem. A recent and important investigation by Gainer and colleagues ${ }^{27}$ has identified 5 main themes that are important to the frail older adult and their caregivers - educational barriers, educational facilitators, patient autonomy and perceived autonomy, patient and family expectations of care, and decision-making advocates-that are likely impactful to frail older adults and their caregivers. A consistent barrier within each of these themes is the perception of a time constraint in the current consent process. These findings have been observed in both cardiac and noncardiac patient populations wherein the development of decision aids or the implementation of a decisional "coach" has been advocated to facilitate a shared-decision making process in patients with chronic conditions facing decisions involving invasive, preference-sensitive therapy options. $^{28}$ As stated by Gainer and colleagues, ${ }^{27}$ given "... the trend toward older and frail patients referred for complex cardiac procedures, the need for an effective shared decision making process is compelling..." for the modern perioperative cardiac surgery team.

\section{CONCLUSIONS}

It is increasingly clear that the cardiac surgery community needs to actively participate in initiatives that address the perioperative management of the vulnerable, frail patient to improve the outcomes. This needs to be in the form of implementation of routine frailty assessments and targeted treatment of frail patients, knowledge translation, and the launch of high-quality clinical trials to de-frail our patients. The Essential Frailty Toolset and CFS are 2 practical, evidence-based scales of frailty. Ultimately, such frailty assessment may be used to help guide patient selection and shared decision making for surgery, as well as informing future studies of preoperative and postoperative interventions aimed at improving outcomes in frail patients at highest risk of adverse sequelae. 


\section{Conflict of Interest Statement}

R.C.A. has received an unrestricted educational grant from Pfizer Canada Inc, and honoraria from Mallinckrodt Pharmaceuticals for work unrelated to this article. All other authors have nothing to disclose with regard to commercial support.

\section{References}

1. Jung P, Pereira MA, Hiebert B, Song X, Rockwood K, Tangri N, Arora RC. The impact of frailty on postoperative delirium in cardiac surgery patients. $J$ Thorac Cardiovasc Surg. 2015;149:869-75.

2. Lytwyn J, Stammers AN, Kehler DS, Jung P, Alexander B, Hiebert BM, et al. The impact of frailty on functional survival in patients 1 year after cardiac surgery. $J$ Thorac Cardiovasc Surg. 2017;154:1990-9.

3. Mariotto A, De Leo D, Buono MD, Favaretti C, Austin P, Naylor CD. Will elderly patients stand aside for younger patients in the queue for cardiac services? Lancet (London, England). 1999;354:467-70.

4. Bouma BJ, van den Brink RB, Zwinderman K, Cheriex EC, Hamer HH, Lie KI, Tijssen JG. Which elderly patients with severe aortic stenosis benefit from surgical treatment? An aid to clinical decision making. J Heart Valve Dis. 2004;13: 374-81.

5. Arora RC, Djaiani G, Rudolph JL. Detection, prevention, and management of delirium in the critically ill cardiac patient and patients who undergo cardiac procedures. Can J Cardiol. 2017;33:80-7.

6. Fried LP, Tangen CM, Walston J, Williamson JD, Anderson G. Untangling the concepts of disability, frailty, and comorbidity: implications for improved targeting and care. J Gerontol A Biol Sci Med Sci. 2001;56: M146-56.

7. Fedarko NS. The biology of aging and frailty. Clin Geriatr Med. 2011;27:27-37.

8. Neupane I, Arora RC, Rudolph JL. Cardiac surgery as a stressor and the response of the vulnerable older adult. Exp Gerontol. 2017;87(Pt B):168-74.

9. O'Neill DE, Knudtson ML, Kieser TM, Graham MM. Considerations in cardiac revascularization for the elderly patient: age isn't everything. Can J Cardiol. 2016;32:1132-9.

10. Lavie CJ, Alpert MA, Arena R, Mehra MR, Milani RV, Ventura HO. Impact of obesity and the obesity paradox on prevalence and prognosis in heart failure. JACC Heart Fail. 2013;1:93-102.

11. Zamboni M, Rossi AP, Corzato F, Bambace C, Mazzali G, Fantin F. Sarcopenia, cachexia and congestive heart failure in the elderly. Endocr Metab Immune Disord Drug Targets. 2013;13:58-67.

12. Sepehri A, Beggs T, Hassan A, Rigatto C, Shaw-Daigle C, Tangri N, Arora RC. The impact of frailty on outcomes after cardiac surgery: a systematic review. $J$ Thorac Cardiovasc Surg. 2014;148:3110-37.

13. Arnaoutakis GJ, George TJ, Alejo DE, Merlo CA, Baumgartner WA, Cameron DE, Shah AS. Society of Thoracic Surgeons risk score predicts hospital charges and resource utilization after aortic valve replacement. J Thorac Cardiovasc Surg. 2011;142:650-5.

14. Hubbard RE, Story DA. Does frailty lie in the eyes of the beholder? Heart Lung Circ. 2015;24:525-6.
15. Hogan DB, Maxwell CJ, Afilalo J, Arora RC, Bagshaw SM, Basran J, et al. A scoping review of frailty and acute care in middle-aged and older individuals with recommendations for future research. Can Geriatr J. 2017;20:22-37.

16. Rockwood K, Song X, MacKnight C, Bergman H, Hogan DB, McDowell I, Mitnitski A. A global clinical measure of fitness and frailty in elderly people. CMAJ. 2005; 173:489-95.

17. Lee DH, Buth KJ, Martin B-J, Yip AM, Hirsch GM. Frail patients are at increased risk for mortality and prolonged institutional care after cardiac surgery. Circulation. 2010;121:973-8.

18. Afilalo J, Mottillo S, Eisenberg MJ, Alexander KP, Noiseux N, Perrault LP. Addition of frailty and disability to cardiac surgery risk scores identifies elderly patients at high risk of mortality or major morbidity. Circ Cardiovasc Qual Outcomes. 2012;5:222-8.

19. Afilalo J, Eisenberg MJ, Morin J-F, Bergman H, Monette J, Noiseux N, et al. Gait speed as an incremental predictor of mortality and major morbidity in elderly patients undergoing cardiac surgery. J Am Coll Cardiol. 2010;56:1668-76.

20. Afilalo J, Lauck S, Kim DH, Lefèvre T, Piazza N, Lachapelle K, et al. Frailty in older adults undergoing aortic valve replacement. J Am Coll Cardiol. 2017;70: 689-700.

21. Green P, Woglom AE, Genereux P, Daneault B, Paradis JM, Schnell S, et al. The impact of frailty status on survival after transcatheter aortic valve replacement in older adults with severe aortic stenosis: a singlecenter experience. JACC Cardiovasc Interv. 2012;5:974-81.

22. Barili F, Pacini D, Capo A, Rasovic O, Grossi C, Alamanni F, et al. Does EuroSCORE II perform better than its original versions? A multicentre validation study. Eur Heart J. 2013;34:22-9.

23. Arora RC, Manji RA, Singal RK, Hiebert B, Menkis AH. Outcomes of octogenarians discharged from the hospital after prolonged intensive care unit length of stay after cardiac surgery. J Thorac Cardiovasc Surg. 2017;154: 1668-78.e2.

24. Arthur HM, Daniels C, McKelvie R, Hirsh J, Rush B. Effect of a preoperative intervention on preoperative and postoperative outcomes in low-risk patients awaiting elective coronary artery bypass graft surgery. A randomized, controlled trial. Ann Intern Med. 2000;133:253-62.

25. Sawatzky J-AV, Kehler DS, Ready AE, Lerner N, Boreskie S, Lamont D, et al. Prehabilitation program for elective coronary artery bypass graft surgery patients: a pilot randomized controlled study. Clin Rehabil. 2014;28:648-57.

26. Goldfarb M, Bendayan M, Rudski LG, Morin JF, Langlois Y, Ma F, et al. Cost of cardiac surgery in frail compared with nonfrail older adults. Can J Cardiol. 2017; 33:1020-6.

27. Gainer RA, Curran J, Buth KJ, David JG, Légaré J-F, Hirsch GM. Toward optimal decision making among vulnerable patients referred for cardiac surgery: a qualitative analysis of patient and provider perspectives. Med Decis Making. 2017;37:600-10.

28. Blumenthal-Barby JS, Kostick KM, Delgado ED, Volk RJ, Kaplan HM, Wilhelms LA, et al. Assessment of patients' and caregivers' informational and decisional needs for left ventricular assist device placement: Implications for informed consent and shared decision-making. J Heart Lung Transplant. 2015; $34: 1182-9$.

Key Words: cardiac surgery, frailty 
TABLE E1. Summary of measures to detect frailty in acute care settings

\begin{tabular}{|c|c|c|c|c|c|}
\hline Characteristic & $\begin{array}{c}\text { Judgment-based } \\
\text { measure }\end{array}$ & $\begin{array}{c}\text { Physical performance } \\
\text { measure }\end{array}$ & Physical frailty & Multidimensional frailty & FI \\
\hline Description & $\begin{array}{l}\text { Determination of } \\
\text { frailty based on } \\
\text { the judgment } \\
\text { of a clinician }\end{array}$ & $\begin{array}{r}\text { Use of a single physical } \\
\text { performance measure } \\
\text { to categorize patients }\end{array}$ & $\begin{array}{l}\text { Based on a belief in a } \\
\text { frailty phenotype; } \\
\text { frailty defined as being } \\
\text { present if a certain } \\
\text { number of criteria are } \\
\text { present (rules based) }\end{array}$ & $\begin{array}{l}\text { Extension of physical } \\
\text { frailty to include other } \\
\text { dimensions (eg, } \\
\text { cognition, disability/ } \\
\text { function, psychologic } \\
\text { state, morbidities, self- } \\
\text { rated health, sensory } \\
\text { deficits, social) }\end{array}$ & $\begin{array}{l}\text { Assesses the } \\
\text { accumulation of } \\
\text { deficits predisposing } \\
\text { to adverse outcomes; } \\
\text { calculated as total } \\
\text { number of items } \\
\text { (deficits) present } \\
\text { divided by maximum } \\
\text { potential number }\end{array}$ \\
\hline No. of items & 1 & 1 & $3-5$ & $5-20$ & $30+$ \\
\hline Examples & $\begin{array}{l}\text { "Eyeball" or } \\
\text { "end-of-the-bed", } \\
\text { subjective } \\
\text { assessment }^{\mathrm{E} 1, \mathrm{E} 2} \text {; } \\
\text { Subjective Frailty } \\
\text { Score }^{\mathrm{E} 3} \text {; Canadian } \\
\text { Study of Health } \\
\text { and Aging CFS }\end{array}$ & $\begin{array}{l}\text { Chair stands; gait speed; } \\
\text { grip strength }^{\text {E5-E9 }}\end{array}$ & $\begin{array}{l}\text { Cardiovascular Health } \\
\text { Study criteria }{ }^{\mathrm{E} 10, \mathrm{E} 11} \text {; } \\
\text { Study of Osteoporosis } \\
\text { Fractures scale }{ }^{\mathrm{E} 12} \text {; } \\
\text { Survey of Health, } \\
\text { Ageing and Retirement } \\
\text { in Europe } \mathrm{FI}^{\mathrm{E} 13}\end{array}$ & $\begin{array}{l}\text { Conselice Study of Brain } \\
\text { Aging index; } \\
\text { Edmonton Frail } \\
\text { Scale }^{\mathrm{E} 14} \text {; Fatigue, } \\
\text { Resistance, } \\
\text { Ambulation, and } \\
\text { Loss }^{\mathrm{E} 15} \text {; derived from a } \\
\text { standardized }^{\text {comprehensive }} \\
\text { geriatric assessment }^{\mathrm{E} 16} \text {; } \\
\text { Frailty Trait Scale }^{\mathrm{E} 17} ; \\
\text { Gérontopôle Frailty } \\
\text { Screening Tool; } \\
\text { Groningen Frailty } \\
\text { Indicator } \\
\text { Frailty } \text {; Tilburg } \\
\text { Fricator }\end{array}$ & $\begin{array}{l}\text { FI (various } \\
\quad \text { iterations) }^{\mathrm{E} 11, \mathrm{E} 20}\end{array}$ \\
\hline Comments & $\begin{array}{l}\text { Subjective } \\
\text { assessments open } \\
\text { to potential bias } \\
\text { and concerns } \\
\text { about reliability; } \\
\text { can be based on } \\
\text { multidimensional } \\
\text { frailty assessment }\end{array}$ & $\begin{array}{l}\text { Quick and easy to perform } \\
\text { (although may require } \\
\text { equipment); similar to } \\
\text { physical frailty; does } \\
\text { not capture complex } \\
\text { nature of frailty; } \\
\text { impairments may be } \\
\text { due to factors other than } \\
\text { frailty; many older } \\
\text { patients unable to } \\
\text { complete testing }\end{array}$ & $\begin{array}{l}\text { Widely used; results } \\
\text { typically reported as } \\
\text { frailty category } \\
\text { membership (eg, } \\
\text { nonfrail, prefrail, } \\
\text { frailt), although for } \\
\text { some instruments }{ }^{\mathrm{E} 13} \text { a } \\
\text { continuous frailty score } \\
\text { can be calculated; } \\
\text { criticized for excluding } \\
\text { nonphysical domains }\end{array}$ & $\begin{array}{l}\text { Uncertainty of which } \\
\text { dimensions to include, } \\
\text { how to assess and then } \\
\text { combine them; scales } \\
\text { using different domains } \\
\text { identify different } \\
\text { subgroups; with } \\
\text { increasing item number } \\
\text { becomes similar to FI }\end{array}$ & $\begin{array}{l}\text { Criticized as } \\
\text { containing too many } \\
\text { items with issues of } \\
\text { feasibility; unclear it } \\
\text { has clinically } \\
\text { significant } \\
\text { advantages to } \\
\text { simpler approaches }\end{array}$ \\
\hline
\end{tabular}

$F I$, Frailty index; $C F S$, Clinical Frailty Scale. Adapted from Hogan and colleagues. ${ }^{15}$ 


\section{E-References}

E1. Hubbard RE, Story DA. Patient frailty: the elephant in the operating room. Anaesthesia. 2014;69(Suppl 1):26-34.

E2. Speir A. Defining frailty: "I know it when I see it." J Thorac Cardiovasc Surg. 2015;149:875-6.

E3. Hii TBK, Lainchbury JG, Bridgman PG. Frailty in acute cardiology: comparison of a quick clinical assessment against a validated frailty assessment tool. Heart Lung Circ. 2015;24:551-6.

E4. Rockwood K. A global clinical measure of fitness and frailty in elderly people. Can Med Assoc J. 2005;173:489-95.

E5. Stanaway FF, Gnjidic D, Blyth FM, Le Couteur DG, Naganathan V, Waite L, et al. How fast does the Grim Reaper walk? Receiver operating characteristics curve analysis in healthy men aged 70 and over. BMJ. 2011:343:d7679.

E6. Studenski S, Perera S, Patel K, Rosano C, Faulkner K, Inzitari M, et al. Gait speed and survival in older adults. JAMA. 2011;305:50-8.

E7. Schwenk M, Howe C, Saleh A, Mohler J, Grewal G, Armstrong D, et al. Frailty and technology: a systematic review of gait analysis in those with frailty. Gerontology. 2014;60:79-89.

E8. Cesari M. Role of gait speed in the assessment of older patients. JAMA. 2011; 305:93-4.

E9. Gill TM, Baker DI, Gottschalk M, Peduzzi PN, Allore H, Byers A. A program to prevent functional decline in physically frail, elderly persons who live at home. N Engl J Med. 2002;347:1068-74.

E10. Fried LP, Cardiovascular Health Study Collaborative Research Group. Frailty in older adults: evidence for a phenotype. J Gerontol A Biol Sci Med Sci. 2001:56:M146-56.
E11. Bouillon K, Kivimaki M, Hamer M, Sabia S, Fransson EI, Singh-Manoux A, et al. Measures of frailty in population-based studies: an overview. BMC Geriatr. 2013;13:64.

E12. Ensrud KE, Ewing SK, Taylor BC, Fink HA, Cawthon PM, Stone KL, et al. Comparison of 2 frailty indexes for prediction of falls, disability, fractures, and death in older women. Arch Intern Med. 2008;168:382-9.

E13. Romero-Ortuno R, Walsh CD, Lawlor BA, Kenny RA. A frailty instrument for primary care: findings from the Survey of Health, Ageing and Retirement in Europe (SHARE). BMC Geriatr. 2010;10:57.

E14. Rolfson DB, Majumdar SR, Tsuyuki RT, Tahir A, Rockwood K. Validity and reliability of the Edmonton Frail Scale. Age Ageing. 2006;35:526-9.

E15. Morley JE, Vellas B, Van Kan GA, Anker SD, Bauer JM, Bernabei R, et al. Frailty consensus: a call to action. J Am Med Dir Assoc. 2013;14:392-7.

E16. Jones DM, Song X, Rockwood K. Operationalizing a frailty index from a standardized comprehensive geriatric assessment. J Am Geriatr Soc. 2004;52: 1929-33.

E17. García-García FJ, Carcaillon L, Fernandez-Tresguerres J, Alfaro A, Larrion JL, Castillo C, et al. A new operational definition of frailty: the Frailty Trait Scale. J Am Med Dir Assoc. 2014;15:371.e7.

E18. Peters LL, Boter H, Buskens E, Slaets JPJ. Measurement properties of the Groningen Frailty Indicator in home-dwelling and institutionalized elderly people. J Am Med Dir Assoc. 2012;13:546-51.

E19. Gobbens RJJ, van Assen MALM, Luijkx KG, Wijnen-Sponselee MT, Schols JMGA. The Tilburg frailty indicator: psychometric properties. J Am Med Dir Assoc. 2010;11:344-55.

E20. Searle SD, Mitnitski A, Gahbauer EA, Gill TM, Rockwood K. A standard procedure for creating a frailty index. BMC Geriatr. 2008;8:24 